\title{
Terminologia Baniwa relacionada às palmeiras ${ }^{1}$
}

Madalena Otaviano Aguiar ${ }^{2,4}$ e Maria Silvia de Mendonça ${ }^{3}$

Recebido em 18/11/2010. Aceito em 9/05/2011

\section{RESUMO}

(Terminologia Baniwa relacionada às palmeiras). O presente estudo faz uma análise da terminologia dos nomes dados às palmeiras (Arecaceae) pelos índios Baniwa da comunidade indígena de Tunuí Cachoeira, alto rio Negro, AM, Brasil, com o objetivo de obter a tradução e/ou a significação das palavras. As coletas de dados foram feitas com aplicação de entrevistas estruturadas diretas e pessoais e semi-estruturadas em estudo de grupo e turnês-guiadas. A partir da análise dos termos, foi possível reconhecer características de nomeação relacionadas à morfologia (58\%), à ecologia (29\%) e à cultura (13\%). Também foi possível evidenciar que há termos superordenados (genéricos) que relacionam por inclusão hierárquica os subordinativos (específicos), indicando uma categorização e subcategorização em ordem descendente. Isto está de acordo com o modelo berliniano que nomeia de lexema primário e secundário, respectivamente. Estas análises contribuem para uma melhor compreensão do conhecimento tradicional do povo Baniwa.

Palavras-chave: Arecaceae, Etnobotânica, Nomenclatura etnobiológica, Índios Baniwa

\begin{abstract}
(Baniwa terminology related to Palms). The present study analyzes the naming terminology given to the palms (Arecaceae) by the Baniwa Indians of the indigenous community of Tunuí Cachoeira, in the Upper Rio Negro, Amazonas, Brazil, in order to obtain the translation and/or the meaning of the words. Data collection was achieved through the use of direct structured and semi-structured personal interviews, group study, and guided site-visits (to the plants in question). In analyzing the terms, it was possible to recognize naming characteristics tied to morphology (58\%), ecology (29\%) and culture (13\%). It also was possible to demonstrate that there are superordinate terms (generics) that connect by hierarchical inclusion the subordinate categories (specifics), indicating a categorization and subcategorization in descending order. This is in accord with the Berlinian model which names the primary lexeme and secondary lexeme, respectively. These analyses contribute to a better understanding of the traditional knowledge of the Baniwa people.
\end{abstract}

Key words: Arecaceae, Ethnobotany, Ethnobiological Nomenclature, Baniwa Indians

\section{Introdução}

Na região do alto e médio rio Negro há uma grande riqueza cultural e linguística, sendo faladas mais de vinte línguas pertencentes a quatro grandes famílias linguísticas: Tukano Oriental, Aruak, Maku e Yanomami. A língua Baniwa pertence à família linguística Aruak (=Arawak) e é muito parecida com a língua Kuripako, como o português e o espanhol, e são frequentes os casamentos entre os dois grupos étnicos. Os índios Baniwa e os Kuripako ocupam toda a bacia do rio Içana, afluente do alto rio Negro, residentes em mais de 90 povoados, entre comunidades e sítios, com uma população total de cerca de cinco mil indivíduos. No Brasil, os povoados Baniwa estão localizados no baixo e médio rio Içana e os Kuripako somente no alto rio Içana (Calbazar \& Ricardo 2006).

São catalogadas mais de 180 línguas indígenas em uso corrente no Brasil. Três delas ganharam a condição de idioma oficial, ao lado do português, no município de São Gabriel da Cachoeira, região do alto rio Negro, onde vigora uma lei que co-oficializa as línguas Nheengatu, Tukano e Baniwa, lei 145/2002, aprovada em 22/11/2002 (Lei municipal oficializa línguas indígenas 2009).

Os trabalhos de Ramirez (2001a,b) configuram-se entre os estudos mais completos sobre a língua indígena baniwa. $\mathrm{O}$ autor considera que dentro do idioma Baniwa-Kuripako existem variações dialetais que não impedem a compreensão, identifica três super-dialetos e suas localizações: Dialeto

\footnotetext{
Parte da tese de Doutorado da primeira Autora

2 Instituto Federal de Educação, Ciência e Tecnologia do Amazonas, Campus São Gabriel da Cachoeira, São Gabriel da Cachoeira, AM, Brasil

3 Universidade Federal do Amazonas, Faculdade de Ciências Agrárias, Manaus, AM, Brasil

4 Autor para correspondência: aguiarmada@yahoo.com.br
} 
Central, Dialeto Setentrional e Dialeto Meridional. Há zonas de tensão linguística, como na região de Tunuí, onde se ouve um falar de transição entre os dialetos central e meridional. $\mathrm{O}$ mesmo faz um estudo lingüístico sobre as línguas Arawak de toda a Amazônia Sententrional. Ainda, compôs o dicionário Baniwa-Português no qual afirma que o falar de referência é o Super-Dialeto Central, especialmente, o que se escuta no rio Içana e seus afluentes, rio Aiari e Cuiari, em cuja área de abrangência está inserida a comunidade estudada, Tunuí Cachoeira, referenciada pelo autor como área de tensão linguística.

Um marco nos estudos orientados cognitivamente sobre semântica (estudo do significado linguístico) deu-se na década de 1950, com o trabalho pioneiro de Conklin que concentrou mais atenção sobre aspectos lexicográficos e análises semânticas dos sistemas de classificação de folk. Segundo Conklin (1962), a estrutura semântica das classificações de folk é de suma importância, pois, de sua análise, depende a precisão de muitas afirmações cruciais sobre a cultura em questão.

O presente estudo faz uma análise dos termos baniwa relacionados às palmeiras (Arecaceae), com o objetivo de obter a tradução e/ou a significação das palavras em português, a fim de descrever os princípios envolvidos na nomenclatura baniwa, isolar os táxons das categorias taxonômicas, obtendo informações sobre eles e, ainda, discutir esses dados com base nas análises etnossemânticas encontradas nos trabalhos de Berlin et al. (1973) e Couto (2007), tendo como principal fonte de consulta da correção da grafia e da interpretação em português dos termos indígenas, os trabalhos de Raminez (2001a,b) e os especialistas na língua indígena Baniwa.

\section{Material e métodos}

O estudo foi realizado entre os Baniwa, moradores da comunidade indígena de Tunuí Cachoeira, situada na região do médio rio Içana, afluente do rio Negro, no município de São Gabriel da Cachoeira, Estado do Amazonas, com coordenadas geográficas do centro da aldeia: $01^{0} 23^{\prime} 26^{\prime \prime} \mathrm{N} / 68^{\circ} 10^{\prime} 32^{\prime \prime} \mathrm{W}$, altitude $112 \mathrm{~m}$. A comunidade é formada por cerca de 250 habitantes falantes da língua baniwa. Foram realizadas sete viagens à comunidade, iniciadas em maio de 2007 e finalizadas em outubro de 2008, com estadias de 22, 20,16, 25, 15, 18 e 10 dias, totalizando 126 dias.

As coletas de dados etnobotânicos foram feitas através de entrevistas estruturadas e semi-estruturadas aos moradores pertencentes à etnia Baniwa, acima de 12 anos, de ambos os sexos. Foram realizadas com a intervenção de um intérprete, denominado mediador, para fazer a interlocução entre o entrevistador (pesquisador) e os entrevistados (indígenas), em virtude da dificuldade que os moradores têm de se comunicar em português, principalmente, os adultos, em especial os idosos.
Participaram da pesquisa oito mediadores falantes da língua baniwa e da língua portuguesa, perspicazes e capazes de transmitir informações com originalidade, confiabilidade e clareza. Eles também acrescentaram informações enriquecedoras à pesquisa, bem como, indicaram os especialistas locais, indivíduos com excelente conhecimento das plantas da região, denominados de informantes-chave, que também indicaram outros, ocorrendo o que é denominado por Bailey (1994 apud Albuquerque et al. 2008) de "bola de neve" (snow ball).

As primeiras entrevistas foram realizadas com questões estruturadas, aplicadas individualmente. Foram feitas através de formulário (preenchido pelo entrevistador) e questionários (preenchidos pelos entrevistados), conduzidos a 95 e 44 informantes entrevistados, respectivamente. Cada um deles nomeou as palmeiras que conhecia, gerando uma lista de nomes indígenas, seguido do vernáculo da comunidade ou da tradução em português, do local de ocorrência e da importância cultural (uso e das formas de uso). No questionário continha uma única questão traduzida em baniwa e em português: Pidana nepitana nhaaha haiko makeperitsa phianhenipe? Quais as palmeiras que você conhece? Este método objetivou elucidar através da escrita, nomes indígenas de difícil compreensão na linguagem auditiva. O método de questionário foi pouco aceito pelos indígenas, principalmente, entre os adultos e idosos que têm dificuldades ou não sabem a grafia baniwa.

Posteriormente, foram feitas entrevistas com os informantes-chave, conduzidas individual ou coletivamente através de estudos em grupo, ocorridos em vários momentos da pesquisa, a partir de questões parcialmente formuladas (semi-estruturadas), que é uma forma de obter informações e dar flexibilidade a novas sugestões, críticas e reflexões, em que as mesmas podem ser refutadas, validadas ou complementadas. A presença do pesquisador figurou como um facilitador na condução do diálogo, não impondo suas próprias idéias, o que contribuiu para a participação e a reflexão do entrevistado, proporcionando a construção de diagnósticos e soluções realizados pelos próprios indígenas. Adaptadas a uma estratégica de investigação êmica (Posey 1987), foram entrevistados onze informantes-chave.

Estímulos visuais foram utilizados como uma estratégica adicional para que os participantes pudessem identificar as palmeiras ou lembrar de determinados tipos de informações de interesse da pesquisa ou, ainda, para localizar o entrevistado contextualmente (Alburquerque et al. 2008).

Foram mostrados aos informantes-chave produtos derivados das plantas, como partes da planta fresca, fotografias de palmeiras registradas em literaturas especializadas (Ribeiro et al. 1999; Miranda et al. 2001; Lorenzi et al.2004) e imagens digitais registradas in situ com câmera digital SONY 7.2 mega pixels. Foi feito o checklist-entrevista a partir das listas de plantas citadas nas entrevistas estruturadas pelos informantes entrevistados. Também foram realizadas turnês-guiadas que consistiu em levar o 
informante-chave a uma ou mais zonas vegetacionais com o objetivo de obter informações sobre a planta, também referida como "ethnobotanical inventory" (Boom 1987), "walk-in-the-woods" (Philips \& Gentry 1993) e "field interview" (Alexiades 1996).

As análises dos termos foram feitas com base no modelo berliniano (Berlin et al. 1973; Berlin 1973; 1992), Raminez (2001a,b), Couto (2007) e por especialistas na língua indígena baniwa, com a participação efetiva dos mediadores.

Foram concedidas autorizações da Fundação Nacional do Índio - FUNAI, regional e de Brasília, para coleta e a realização de pesquisa em Unidades de Conservação Federais, ${ }^{\circ}$ do processo 1829/06; do Comitê de Ética em Pesquisa com Seres Humanos-CEP/UFAM, para acesso a componentes do patrimônio genético com conhecimento tradicional associado (CAAE $\mathrm{n}^{\circ}$ 0019.0.115.115-07); e do Conselho de Gestão do Patrimônio Genético-CGEN, ${ }^{\circ}$ 023/2007, publicado em Diário Oficial a Deliberação de ${ }^{\circ}$ 207, de 30 de agosto de 2007.

\section{Resultados e discussão}

Os Baniwa não conhecem o termo "palmeira" (Arecaceae ou Palmae). Eles se referem às mesmas pelo termo "háiko makeperi" que significa em português "plantas sem galhos" (háiko=planta, ma=sem, keperi=galhos). Diante desse fato, houve o cuidado de não dar nenhuma definição às palmeiras. As entrevistas foram iniciadas mostrando algumas espécies comuns na paisagem baniwa, como o açaí, que é muito abundante na aldeia. Consequentemente, as listas geradas contêm nomes que não designam as palmeiras e não foram discutidos no presente estudo, visto que $o$ artigo refere-se à terminologia baniwa das palmeiras não pretendendo, portanto, abranger outras plantas.

Das entrevistas individuais, com aplicação de formulários e questionários, foram obtidos 108 e 111 nomes indígenas, respectivamente, e dos estudos em grupo e turnês-guiadas foram obtidos 98 nomes. A compilação dessas informações resultou numa lista com 134 nomes indígenas relacionados às palmeiras que foram validados nos estudos em grupo e turnês-guiadas (Tab. 1).

Os nomes das palmeiras foram citados na língua Baniwa, exceto para três deles: Douripe, Olixe (em língua indígena kuripako) e Yáara (em nheengatu). Os dois primeiros são pouco conhecidos entre os moradores, foram citados poucas vezes, sendo para Douripe uma vez nas entrevistas com formulário e para Olixe quatro vezes com questionário, veja na tabela 1 (item 11 e 70). Ambos foram identificados de forma duvidosa pelo vernáculo "tucum" e "caranaí-domato", respectivamente. Ao contrário, o nome Yáara (item 131) foi bastante citado (12 vezes), sendo popularmente conhecido entre os moradores. Somente os mais idosos sabem reconhecer que o nome Yáara, em nheengatu, corresponde ao Manekoli, em baniwa, e trata-se de uma palavra em desuso pelos baniwa. Desta forma, o nome Manekoli foi considerado como o termo baniwa relacionado à palmeira e o nome Yáara como o seu vernáculo.

O método de entrevista com aplicação de questionário, apesar de pouco aceito pelos indígenas, foi de importante contribuição nas análises dos termos, visto que, possibilitou identificar através da grafia, nomes indígenas difíceis de compreender na linguagem oral. Um exemplo, Koronhe (item 37) e Koroñhe (item 38) são nomes semelhantes, tanto na forma verbal quanto na escrita, mas nomeiam táxons distintos, cujo vernáculo é coquito e tucumã-í, respectivamente. Assim também para os nomes semelhantes na expressão verbal e escrita que identificam um mesmo táxon, como seguem: Maalipóne (=Máali-ipóne) e Maaliponeni (=Máali-ipopeni) (item 46), Makowaátshi e Makoátshi (item 53), Paitsi-dówire e Paitsi-idówire (item 71). Também revelou as formas gráficas de Eeña atual e Heeña mais antiga (item 17). Todas essas formas de palavras estão corretas, apesar de grafadas diferentes, pois não impedem a compreensão do termo.

No dicionário Baniwa-Português (Raminez 2001b), Makoátshi é identificado como uma variedade de Makowaátshi, o que não está de acordo com a identificação feita pelos informantes-chave que consideram referir-se ao mesmo táxon. Eles também verificam que a grafia mais correta é Paitsi-idówire que em português significa "espinho de rã" (páitsi=rã, dóowiri=espinho), cujo prefixo $\mathbf{i}$ (i-dówire) indica o possuidor "de", a mesma regra se aplica para Attíne-iponamani (=patauá de jacamim), Dzawíraidówire (=espinho de acará), Máali-ipóne (=ubim de garça), Napiríkoli-ipíipiri (=pupunha-de-Deus) e outros.

Os termos baniwa doopara (item 3), likoiro (item 45), makoára (item 52) e porámo (item 107) são habitualmente usados para indicar os táxons Manákhe-doopara (item 58), Manákhe-ikoiro (item 61), Ponáma-makoára (item 99), Póoperi-makoára (item 107) e Manákhe-porámo (item 65), respectivamente. Dificilmente os moradores se referem a eles pelo seu nome composto, como pôde ser verificado pelo número de citações nas entrevistas com aplicação de formulário e questionário (Tab. 1). Segundo Couto (2007), se a referência à coisa em questão se torna muito frequente, por razões de economia, a expressão vai se encurtando, ou seja, evita-se combinação muito longa de elementos.

Os nomes indígenas baniwa relacionados às palmeiras podem ser enquadrados em dois grupos: os "nomes próprios" e os "nomes com características de nomeação".

Os nomes próprios podem ser incluídos na classe dos nomes independentes, reconhecidos por Raminez (2001a,b) no discurso Baniwa-Curripaco, os quais formam uma classe de termos primários e secundários que designam os nomes próprios, os seres humanos ou sobrenaturais, os animais, os vegetais, os elementos da natureza, os objetos e certos estados fisiológicos. Ou, enquadrados no que Couto (2007) classifica de lexema simples, os quais não se deixam decompor em unidades significativas menores, em morfemas ou outras palavras simples, são monomorfêmicos. 


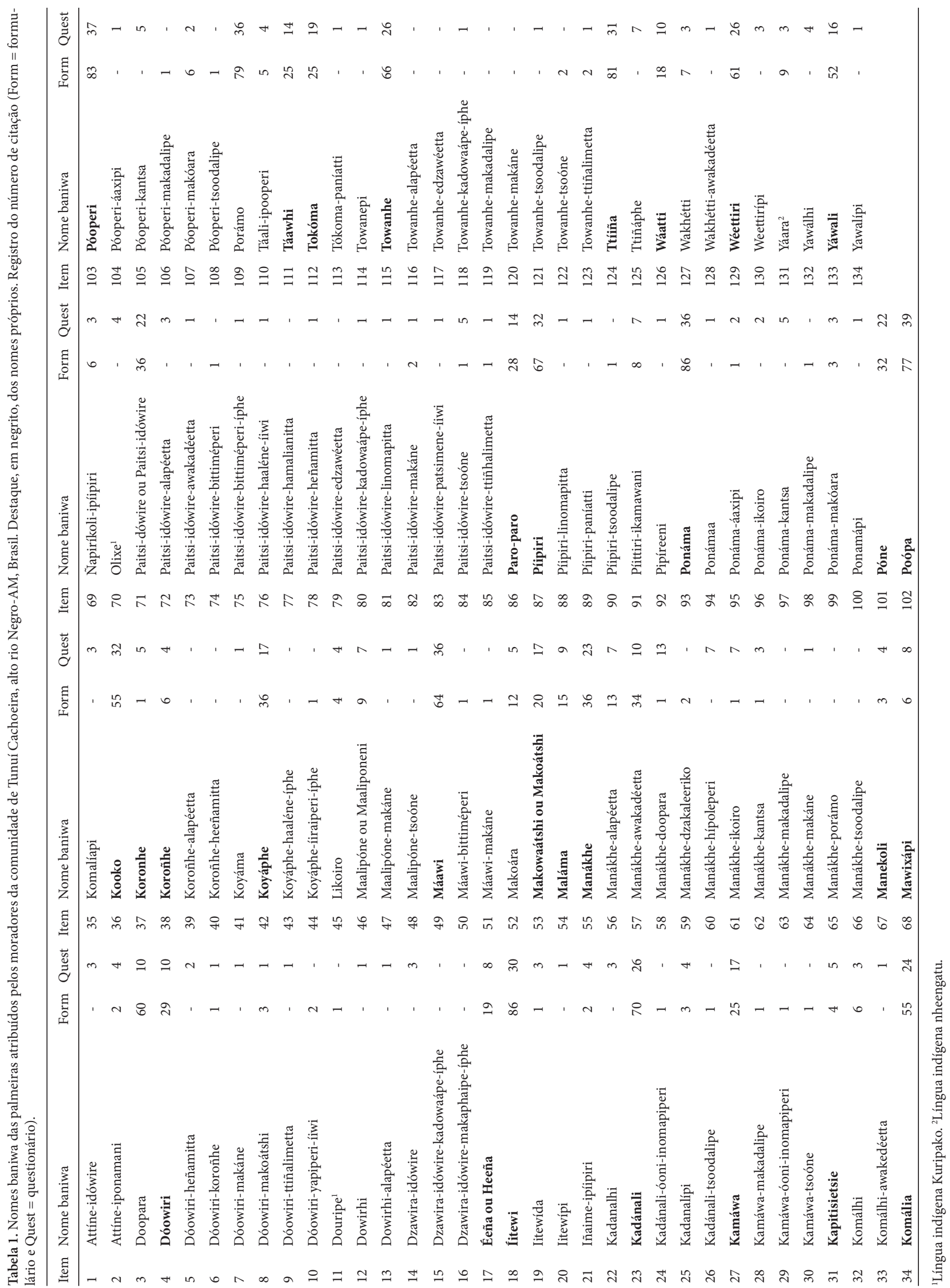


Foram reconhecidos 30 nomes próprios, os quais apresentam estrutura mononomial, exceto Kapitsietsie e Paro-paro que são formas com reduplicação parcial e total, respectivamente. Nos diálogos com os "brancos" (em português) são referidos pelo seu significado em português, ou seja, pelo nome vernáculo da comunidade, exceto Kapitsietsie, cujo vernáculo é desconhecido. No dicionário Baniwa-Português (Raminez 2001b), o nome Mawixápi se refere ao tubo interno da zarabatana (arma de caça), que significa "paxiubinha bucha" ou "bucho de pari". É de consenso dos informantes que os nomes próprios identificam as palmeiras e, em geral, foram os que obtiveram o maior número de citações (Tab. 1).

Os nomes com características de nomeação têm nas suas definições aproximação aos conceitos botânicos e não botânicos da língua portuguesa, podendo assim ser traduzidos. São formados por dois nomes (binominais), três (trinominais) ou quatro (quadromiais) ou apenas morfemas sufixados. Eles podem ser classificados como lexemas complexos que são compostos por outros lexemas, ou apenas polimorfêmicos (Couto 2007). Os morfemas sufixados são denominados por Raminez (2001a,b) de nomes dependentes, os quais são constituídos por termos primários ou secundários que designam as partes do corpo, do objeto ou do espaço, os termos da anatomia animal ou vegetal e os termos de parentesco.

Entre os Baniwa, há o uso comum de termos que se referem aos caracteres morfológicos, ecológicos e culturais, sendo que os termos relacionados à morfologia foram os que obtiveram o maior número de registro (58\%), subdivididos em relação ao tamanho, às partes da planta, à cor e à presença de espinhos, seguidos dos ecológicos (29\%), hábitat e a associação a animais, e dos culturais (13\%), que se referem à origem, ao parentesco, ao cultivo, à mitologia e ao uso das palmeiras (Tab. 2). De acordo com o quinto princípio de nomenclatura do modelo berliniano sumarizado por Berlin (1992:31): "nomes de plantas e animais, comumente fazem alusão metafórica a alguma característica típica morfológicas, comportamentais, ecológicos ou característica qualitativa de seus referentes".

Nas nomeações baniwa, predomina a nomenclatura binomial que está relacionada ao nome específico. Isto está de acordo com o princípio de nomenclatura berliniana para os nomes específicos, segundo o qual, a estrutura dos nomes specific em sistemas de folk é regularmente binomial, em que o nome generic é modificado por um adjetivo que, geralmente, designa alguns caracteres morfológicos para a classe das plantas, tal como a cor, a textura, o tamanho. A nomenclatura binomial baniwa também é a maioria naqueles caracteres de nomeação que estão relacionados à ecologia ou ao cultural.

Nem todos os termos relacionados às palmeiras são utilizados para nomear os táxons, visto que muitos se aplicam às partes da planta, ao ambiente onde a planta se encontra $\mathrm{e}$ a importância cultural (uso). Segundo o modelo berliniano, nomeações apenas semânticas ou puramente de importância cultural e econômica não devem ser usadas para incluir agrupamentos em níveis hierárquicos. De modo sistemático, dos 93 nomes baniwa com características de nomeação relacionada às palmeiras, somente 42 são comumente utilizados para nomear os táxons, distribuídos dentro das características de nomeação da seguinte forma: as características morfológicas somaram $40,48 \%$ das nomeações, seguidas das ecológicas $(35,71 \%)$ e culturais $(23,81 \%)$ (Fig. 1$)$.

O tamanho nem sempre nomeia o táxon, muitas vezes é usado para salientar diferenças morfológicas dentro de um mesmo táxon, vão do diminutivo ao aumentativo, nessa ordem seguem os léxicos: pipíreeni que significa "pupunha pequena” (píipiri=pupunha, -eni=diminutivo), bittiméperi (=pequeno, miúdo ou em fase de crescimento, "plântula"), tsoóne (=pequeno, baixo), kadowaápe (=miúdo), tsoodalipe (=fruto pequeno), yapíperi (=comprido, longo, alto), makáne (=grande, alto), makaphaipe (=grande), makadalipe (=fruto grande). Mas também podem ser usados para identificar os táxons subordinativos, em que um deles é nomeado pelo nome principal superordenado. Geralmente, estes são os mais significantes da categoria, por exemplo, Kamáwa (jacitara) e Píittiri-ikamawani (jacitara de morcego) que também são nomeados de Kamáwa-makáne (jacitara grande) e Kamáwa-tsoóne (jacitara pequena), respectivamente. Os léxicos makoára e porámo são usados para identificar os táxons de frutos pequenos das categorias superordenadas: Ponáma (Ponáma-makoára), Póoperi (Póoperi-makoára) e Manákhe (Manákhe-porámo).

Os termos que indicam as partes da planta são morfemas sufixados que não são empregados na nomenclatura dos táxons. Eles são denominados por Raminez (2001a,b) de classificadores, salientam uma característica animal, vegetal ou de qualquer nome, dos quais o classificador "-pi" designa o caule de palmeira, podem ser usados no modo individual ou coletivo, como komalíapi estipe "pé" de tucum, ponamápi estipes "pés" de patauá ou patauazeiro. O classificador "-phe" designa folha, os "-hi" ou "-da" fruta e o "-lhi" caroço ou semente. Os nomes iináka e íixi significam na língua portuguesa fruta e caroço (Raminez 2001b). Couto (2007) verifica que, quando a árvore é frutífera, em geral ela é chamada pelo nome da fruta e não da árvore em si. Quando é necessário referir-se à árvore, e não ao seu fruto, geralmente se usa a expressão "pé de X".

Os termos que se referem à cor são bastante usados na nomenclatura dos táxons, por exemplo, Koyáphe-haaléneíphe curuá de folha branca (háale=branco), Koyápheíraiperi-íphe curuá de folha vermelha (iirai=vermelho) e o Manákhe-hípoleperi açaí de fruto verde (hípole=verde). Em alusão à cor roxa da raiz da batata-cará (=áaxi), as palmeiras de patauá e bacaba, que têm a coloração da polpa da fruta roxa, recebem o nome da mesma, cujos táxons são identificados por Ponáma-áaxipi e Póoperi-áaxipi.

As palmeiras espinhosas podem ser referenciadas pelos termos dóowiri, doowirína e íiwi, como em dóowiri-ko- 
Tabela 2. Características de nomeação baniwa relacionadas às palmeiras, seguida da tradução em português, atribuídas pelos moradores da comunidade de Tunui Cachoeira, alto rio Negro-AM, Brasil.

\begin{tabular}{|c|c|c|c|}
\hline \multicolumn{2}{|c|}{ Morfologia (tamanho) } & \multicolumn{2}{|c|}{ Morfologia (presença de espinho) } \\
\hline Dóowiri-makáne & Planta espinhosa grande & Dóowiri (Doowirína) & Qualquer planta espinhosa \\
\hline Dóowiri-yapíperi-íiwi & Planta espinhosa de espinho longo & Dóowiri-koroñhe & Planta espinhosa de koroñhe (tucumã-i) \\
\hline Dzawira-idówire-kadowaápe-íphe & Espinho de acará da folha miúda & Dóowiri-makoátshi & Planta espinhosa de makoátshi \\
\hline Dzawira-idówire-makaphaipe-íphe & Espinho de acará da folha graúda & Dóowire-yapiperi-íiwi & Palmeira espinhosa de espinhos longos \\
\hline Kadánali-tsoodalipe & Caranaí-da-beira de fruto pequeno & Paitsi-dówire-patsimene-íiwi & Marajá de espinho mole \\
\hline Kamáwa-makáne & Jacitara de fruto grande & \multicolumn{2}{|c|}{ Ecologia (habitat) } \\
\hline Kamáwa-tsoóne & Jacitara pequena & Dóowiri-heñamitta & Planta espinhosa da capoeira \\
\hline Máawi-bittiméperi & Paxiubinha pequena & Dóowiri-ttiñalimetta & Planta espinhosa do caranazal \\
\hline Máawi-makáne & Paxiubinha de tamanho maior & Dowirhi-alapéetta & Fruto de planta espinhosa do igapó \\
\hline Manákhe-makadalipe & Açaí de fruto grande & Kadánali-óoni-inomapiperi & Caranaí-da-beira do rio \\
\hline Manákhe-makáne & Açaí grande & Kamáwa-óoni-inomapiperi & Jacitara da beira do rio \\
\hline Manákhe-porámo & Açai pequeno & Komálhi-awakedéetta & Caroço de tucum do mato \\
\hline Manákhe-tsoodalipe & Açaí de fruto pequeno & Koroñhe-alapéetta & Tucumã-í que fica no igapó \\
\hline Paitsi-idówire-bittiméperi & Marajá pequeno & Koroñhe-heeñamitta & Tucumã-í que fica na capoeira \\
\hline Paitsi-idówire-bittiméperi-íphe & Marajá de folha miúda & Manákhe-alapéetta & Açaí do igapó \\
\hline Paitsi-idówire-kadowaápe-íphe & Marajá de folha miúda & Manákhe-awakadéetta & Açaí do mato \\
\hline Paitsi-idówire-makáne & Marajá grande & Manákhe-dzakaleeriko & Açaí que fica na área da comunidade \\
\hline Paitsi-idówire-tsoóne & Marajá pequeno & Paitsi-idówire-alapéetta & Marajá do igapó \\
\hline Pipíreeni (-eeni) & Pupunha pequena & Paitsi-idówire-awakadéetta & Marajá do mato, da floresta. \\
\hline Píipiri-tsoodalipe & Pupunha de fruto pequeno & Paitsi-idówire-linomapitta & Marajá da beira do rio \\
\hline Ponáma-makadalipe & Patauá de fruto grande & Paitsi-idówire-ttiñhalimetta & Marajá do caranazal \\
\hline Ponáma-makóara & Patauá de fruto pequeno & Píipiri-linomapitta & Pupunha da beira do rio \\
\hline Póoperi-makadalipe & Bacaba de fruto grande & Towanhe-alapéetta & Caranaí-do-mato que fica no igapó \\
\hline Póoperi-makóara & Bacaba de fruto pequeno & Towanhe-ttiñalimetta & Caranaí-domato que fica no caranazal \\
\hline Póoperi-tsoodalipe & Bacaba de fruto pequeno & Towanhe-edzawéetta & Caranaí-do-mato que fica na terra firme \\
\hline Towanhe-kadowaápe-íphe & Caranaí-do-mato da folha miúda & Wakhétti-awakadéetta & Tucumã do mato \\
\hline Towanhe-makadalipe & Caranaí-do-mato de fruto grande & \multicolumn{2}{|c|}{ Ecologia (associação a animais) } \\
\hline Towanhe-makáne & Caranaí-do-mato grande & Attíne-idówire & Espinho de jacamim \\
\hline Towanhe-tsoodalipe & Caranaí-do-mato de fruto pequeno & Attíne-iponamani & Patauá de jacamim \\
\hline Towanhe-tsoóne & Caranaí-do-mato pequeno & Dzawira-idówire & Espinho de acará \\
\hline \multicolumn{2}{|c|}{ Morfologia (parte da planta) } & Máali-ipóne & Ubim de garça \\
\hline Dowirhi (-hi) & Fruta de planta espinhosa & Paitsi-idówire & Espinho de rã ou marajá \\
\hline Iitewída (-da) & Fruta de buriti & Píittiri-ikamawani & Jacitara de morcego \\
\hline Iitewípi (-pi) & Estipe "pé" de buriti ou buritizeiro & Táali-ipooperi & Bacaba de aracu \\
\hline Kadánalhi (-lhi) & Caroço de caranaí-da-beira & \multicolumn{2}{|c|}{ Cultural (origem) } \\
\hline Kadanalípi (-pi) & Estipe "pé" de caranaí-da-beira & Manákhe-doopara & Açaí do Pará \\
\hline Komálhi (-lhi) & Caroço de tucum & Manákhe-kantsa & Açaí verdadeiro \\
\hline Komalíapi (-pi) & Estipe "pé" de tucum & Ponáma-kantsa & Patauá verdadeiro \\
\hline Ponamápi (-pi) & Estipe "pé" de patauá ou patauazeiro & Póoperi-kantsa & Bacaba verdadeira \\
\hline Towanepi (-pi) & Estipe "pé" de caranaí-do-mato & \multicolumn{2}{|c|}{ Cultural (parentesco) } \\
\hline Ttiñáphe (-phe) & Folha "palma" de caranã & Manákhe-ikoiro & Açaí-solteira \\
\hline Weettirípi (-pi) & Estipe "pés" de inája ou inajazeiro & Ponáma-ikoiro & Patauá-solteira \\
\hline Yawálhi (-lhi) & Caroço de jauari & \multicolumn{2}{|c|}{ Cultural (cultivo) } \\
\hline Yawalípi (-pi) & Estipe "pé" de jauari & Píipiri-paníatti & Pupunha plantada \\
\hline \multicolumn{2}{|c|}{ Morfologia (cor) } & Tókoma-paníatti & Tucumã plantado \\
\hline Koyáphe-haaléne-íphe & Curuá da folha "palaha" branca & \multicolumn{2}{|r|}{ Cultural (mito) } \\
\hline Koyáphe-íraiperi-íphe & Curuá da folha "palha" vermelha & Iñaime-ipíipiri & Pupunha do diabo \\
\hline Manákhe-hípoleperi & Açaí de fruto verde & Ñapiríkoli-ipíipiri & Pupunha de deus \\
\hline Paitsi-idówire-haaléne-íiwi & Marajá de espinho branco & \multicolumn{2}{|r|}{ Cultural (uso) } \\
\hline Ponáma-áaxipi & Pé de patauá de fruto 'polpa' roxo & Koyáma & Tapete feito de koyáphe (curuá) \\
\hline Póoperi-áaxipi & Pé de bacaba de fruto 'polpa' roxo & Ponámaa & Suco "vinho" de patauá \\
\hline
\end{tabular}




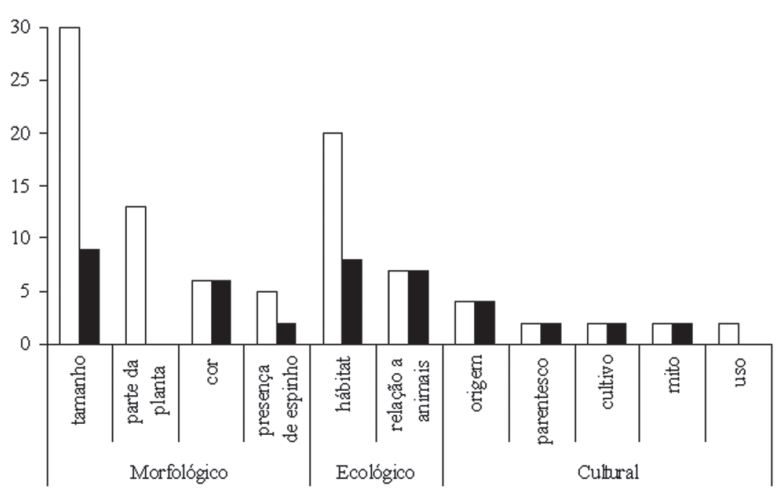

Figura 1. Características de nomeação relacionadas às palmeiras atribuídas pelos Baniwa da comunidade indígena de Tunuí Cachoeira, alto rio Negro-AM, Brasil ( $\square=$ número total de nomes $\boldsymbol{\bullet}=$ número de nomes que nomeiam os táxons).

roñhe planta espinhosa de tucumã-í e dóowiri-makoátshi planta espinhosa de marajá do mato. Detalhes na estrutura morfológica do espinho podem agrupar táxons, como na expressão dóowiri-yapiperi-íiwi (yapíne=comprido, íiwi=espinho) que agrupa as palmeiras que têm espinhos longos, Makoátshi, Koroñhe e outros, bem como a flexibilidade do espinho que nomeia a etnoespécie de Paitsi-idówire-patsimene-íiwi (patsíme=mole) marajá de espinho mole.

A associação da palmeira com o seu habitat é bastante usada entre os indígenas, às vezes parecem descrever mais o ambiente do que as características morfológicas da planta, acrescentando informações importantes sobre o ambiente em que vive a palmeira, resultado das atividades extrativistas desenvolvidas ao longo dos tempos pelos indígenas. Os termos indicadores de ambientes utilizados nas nomeações das palmeiras, como também referidos por Raminez (2001b) e Andrello (2006) foram: alapéetta (alápe = igapó), que fica no igapó; awakadéetta (awakáda = mata, floresta), que fica no mato, ou seja, fora da área de ocupação da comunidade; dzakaleeriko, que fica no entorno da área de ocupação da comunidade; edzawéetta, que fica na terra firme ou terras altas, boa pra fazer roças (éedzawa = terra firme); heeñamitta, que fica na capoeira, roça velha ou abandonada (heéñami = capoeira); linomapitta ou óoni-inomapiperi, que fica na beira do rio (óoni $=$ rio, nomápi $=$ beira); e ttiñalimetta, que fica no caranazal (ttiñalima = tipo de campinarana baixa e aberta onde ocorre o caranã ttíiña).

Cabalzar \& Ricardo (2006) ressaltam que há termos específicos na língua baniwa para designar tipos de vegetação. Trata-se, de fato, de um sistema de classificação baseado na percepção da dominância de diferentes espécies em porções específicas da mata. Citam o termo punamarimã (punama $=$ patauá, rimã $=$ concentração), que pode ser traduzido por "área de patauá" ou mesmo "patauazal”, assim, puperimã (bacabal), puparimã (paxiubal), tinharimã (caranazal) e outros.

Os termos que se referem aos animais são bastante usados para nomear as palmeiras, por exemplo, Dzawira- idówire espinho de acará (dzawíra = acará “peixe”), Maalipóne ubim da garça (máali = garça "ave”), Paitsi-idówire espinho de rã (páitsi = certo tipo de rã comestível "anfíbio”), Attíne-idówire marajá-de-jacamim, Attíne-iponamani patauá-de-jacamim (attíne = jacamim "ave"), Píittiri-ikamawani jacitara do morcego (píittiri = morcego "mamífero"), Táali-ipooperi bacaba de aracu (táali = aracu "peixe"). Hartmann (1968) ao tratar da nomenclatura botânica dos índios Borôro e por encontrar nos nomes zoológicos o maior número de étimos (102), concluiu que os critérios para designação de classificação das plantas estão intimamente ligados a uma concepção do mundo considerada característica de povos caçadores. A relação homem-animal também se encontra nítida na nomenclatura botânica dos Baniwa.

O comportamento cultural indígena relaciona vários termos baniwa atribuídos às palmeiras que podem ser usados para nomear os táxons, com exceção dos relacionados ao uso que evidenciam o objeto usado, por exemplo, koyáma (=tapete feito de curuá) e ponámaa (=vinho feito de fruto de patauá). Desse modo, foram usados vários termos que se referem à origem, ao parentesco, ao cultivo e a mitologia, como seguem: a) origem: Manákhe-doopara açaí que veio do Pará; Manákhe-kantsa, Ponáma-kantsa e Póoperi-kantsa (kantsa=próprio da região "verdadeiro"); b) parentesco: likoiro significa "tia dele" (tia cruzada), aplicado para identificar táxons, dentro de uma população, que se destacam dentre os demais, principalmente, por seu porte alto e robusto. O termo likoiro é empregado não somente para o açaí (Manákhe-ikoiro), mas para qualquer população de palmeiras em que um dos indivíduos se destaca dos demais, por exemplo, nas touceiras de caranaí-da-beira, podem ser visualizados likoiro's (Kadánali-ikoiro), no patauazal (Ponáma-ikoiro). Aqui, foi considerado somente o Manákhe-ikoiro por ser de fácil identificação e mais comumente referenciado pelos baniwa; c) as palmeiras cultivadas são referenciadas pelo termo paníatti (=plantio), nomeadas para a pupunha (Píipiri-paníatti) e tucumã (Tókoma-paníatti); d) mitos: os termos ñapiríkoli, que referencia Deus “criador do mundo" (Ñapiríkoli-iṕíipiri = pupunha-de-Deus), e iñaime "demônio" (Iñaime-ipíipiri = pupunha-do-Diabo). Este último não foi encontrado na área da comunidade e somente um informante disse conhecer. Segundo ele, trata-se de uma palmeira que não ocorre na área estudada e é menor que a pupunha-de-Deus.

Levando-se em consideração a análise etnossemântica dos nomes atribuídos às palmeiras que, habitualmente, nomeiam os táxons, os lexemas registrados se enquadram nos princípios de nomenclatura de folk propostos nos modelos berlinianos, em que os nomes de plantas e animais exibem uma estrutura lexical de um dos dois tipos universais: lexemas primários e secundários. Os lexemas primários podem ser classificados em: não analisável e analisável (produtivo e improdutivo).

A maioria dos lexemas primários é classificada como "não analisável”, corresponde aos "nomes próprios", exceto 
Tabela 3. Análise lexical dos nomes baniwa relacionados às palmeiras: LPNA = primário não analisável, LPAP = primário analisável produtivo.

\begin{tabular}{|c|c|}
\hline Lexema primário & Lexema secundário \\
\hline \multicolumn{2}{|l|}{ Dóowiri (LPNA) } \\
\hline \multirow[t]{2}{*}{ Dzawira-idówire (LPAP) } & Dzawira-idówire-kadowaápe-íphe \\
\hline & Dzawira-idówire-makaphaipe-íphe \\
\hline \multicolumn{2}{|l|}{ Éeña (LPNA) } \\
\hline \multicolumn{2}{|l|}{ Íitewi (LPNA) } \\
\hline \multicolumn{2}{|l|}{ Kadánali (LPNA) } \\
\hline \multirow[t]{2}{*}{ Kamáwa (LPNA) } & Kamáwa-makáne \\
\hline & Píittiri-ikamawani ou Kamáwa-tsoóne \\
\hline \multicolumn{2}{|l|}{ Kapitisietsie (LPNA) } \\
\hline \multicolumn{2}{|l|}{ Komália (LPNA) } \\
\hline \multicolumn{2}{|l|}{ Kooko (LPNA) } \\
\hline \multicolumn{2}{|l|}{ Koronhe (LPNA) } \\
\hline \multicolumn{2}{|l|}{ Koroñhe (LPNA) } \\
\hline \multirow[t]{2}{*}{ Koyáphe (LPNA) } & Koyáphe-haaléne-íphe \\
\hline & Koyáphe-íiraiperi-íphe \\
\hline \multirow[t]{2}{*}{ Máawi (LPNA) } & Máawi-makáne \\
\hline & Mawixápi \\
\hline \multicolumn{2}{|l|}{ Makowaátshi (LPNA) } \\
\hline \multicolumn{2}{|l|}{ Maláma (LPNA) } \\
\hline \multirow[t]{5}{*}{ Manákhe (LPNA) } & Manákhe-doopara ou Manákhe-dzakaleeriko \\
\hline & Manákhe-hípoleperi \\
\hline & Manákhe-ikoiro \\
\hline & Manákhe-kantsa, Manákhe-alapéetta ou Manákhe-awakadeetta \\
\hline & Manákhe-porámo \\
\hline \multicolumn{2}{|l|}{ Manekoli (LPNA) } \\
\hline \multirow[t]{8}{*}{ Paitsi-idówire (LPAP) } & Attíne-idówire \\
\hline & Paitsi-idówire-alapéetta \\
\hline & Paitsi-idówire-háalene-íiwi \\
\hline & Paitsi-idowire-hamalianitta \\
\hline & Paitsi-idowire-heeñamitta \\
\hline & Paitsi-idówire-linomapitta \\
\hline & Paitsi-idówire-patsimene-íiwi \\
\hline & Paitsi-idówire-ttiñhalimetta \\
\hline \multicolumn{2}{|l|}{ Paro-paro (LPNA) } \\
\hline Píipiri (LPNA) & Píipiri-paníatti \\
\hline & Ñapiríkoli-ipíipiri \\
\hline & Iñaime-ipíipiri \\
\hline Ponáma (LPNA) & Attíne-iponamani \\
\hline & Ponáma-áaxipi \\
\hline & Ponáma-kantsa \\
\hline & Ponáma-makóara \\
\hline Póne (LPNA) & Póne-makáne \\
\hline & Máali-ipóne ou Póne-tsoóne \\
\hline Poópa (LPNA) & \\
\hline Póoperi (LPNA) & Póoperi-áaxipi \\
\hline & Póoperi-kantsa \\
\hline & Póoperi-makóara \\
\hline & Táali-ipooperi \\
\hline Táawhi (LPNA) & \\
\hline Tokóma (LPNA) & Tokóma-paníatti \\
\hline & Wakhétti-awakadéetta \\
\hline Towanhe (LPNA) & Towanhe-makáne \\
\hline & Towanhe-ttiñalimetta ou Towanhe-tsoóne \\
\hline Ttíiña (LPNA) & \\
\hline Wáatti (LPNA) & \\
\hline Wéettiri (LPNA) & \\
\hline Yáwali (LPNA) & \\
\hline
\end{tabular}


Mawixápi. Mas, há, também, os lexemas primários analisáveis produtivos, em que um dos constituintes de cada expressão indica uma categoria superordenada a qual pertence o objeto, são eles: Dzawira-idówire (=espinho de acará) e Paitsi-idówire (=espinho de rã). Os lexemas secundários ocorrem quando um dos constituintes da expressão indica uma categoria superordenada para a forma em questão; a diferença é que eles ocorrem em conjuntos de contraste, em que um dos termos aparece em todos os rótulos. Estes correspondem a alguns nomes com "características de nomeação" (Tab. 3).

Ainda, segundo o modelo berliniano, os lexemas primários nomeiam os etnogêneros e os secundários as etnoespécies. Obedecendo a esta estrutura hierárquica, as nomeações usadas para nomear os táxons somam 31 termos superordenados (etnogenéricos) e 44 termos subordinativos (etnoespecíficos), sendo que seis são resultantes de mais de uma nomeação para um mesmo táxon (Kamáwa-tsoóne, Manákhe-alapéetta, Manákhe-awakadéetta, Manákhedzakaleeriko, Poné-tsoóne e Towanhe-tsoóne). Daly (1998) ressalta que para alguns nomes comuns ou indígenas usados entre regiões ou numa mesma região, a mesma espécie pode ter vários nomes e várias espécies podem ter o mesmo nome.

O termo Attíne-idówire é subordinativo (specific) ao termo superordenado (generic) Paitsi-idówire "marajá". Isto é evidenciado quando se analisa o significado ou o nome vernáculo dado pelos baniwa "marajá de jacamim" (attíne $=$ jacamim) $($ Tab. 2). Daly (1998) afirma que o conhecimento de nomes vulgares, a sua etimologia e a sua estrutura conceitual que são usados pode oferecer idéias sobre a cultura estudada, também pode dar a conhecer muito sobre as plantas. Dessa maneira, o autor enfatiza que os nomes comuns, vernáculos ou nativos, devem ser tratados com atenção meticulosa, ou sua informação e sua utilidade se perde.

Os termos relacionados às palmeiras tendem a aumentar naqueles táxons de maior significância cultural, como observado para os utilizados na alimentação, Manákhe, Ponáma e Póoperi, ou indicadores de ambiente, Paitsiidówire (Tab. 2). Posey (1987) e Berlin (1992) concordam que o grau de diferenciação dentro de uma determinada categoria cognitiva, quase que invariavelmente, se referem àquelas classes de organismos que são culturalmente importantes, devem ser um indicador mais forte de utilidade ou importância cultural, oferecendo um guia êmico para investigações posteriores.

\section{Agradecimentos}

As autoras agradecem ao suporte financeiro do Programa Jovem Cientista Amazônida - JCA da Fundação de Amparo à Pesquisa do Estado do Amazonas - FAPEAM, ao Conselho Nacional de Desenvolvimento Científico e
Tecnológico - CNPq, pela concessão da bolsa de estudo à primeira autora e ao Instituto Nacional de Pesquisas da Amazônia - INPA e a Universidade Federal do Amazonas - UFAM, por proporcionarem meios para formação de Recursos Humanos na Região Amazônica.

\section{Referências bibliográficas}

Albuquerque, U.P.; Lucena, R.F.P. \& Cunha, L.V.C. 2008. Métodos e técnicas na pesquisa etnobotânica. Recife, Livro Rápido/ NUPEEA.

Alexiades, M.N. 1996. Selected guidelines for ethnobotanical research: a field manual. New York, The New York Botanical Garden.

Andrello, G. 2006. Classificação Baniwa dos tipos de vegetação. Pp.6869. In: Cabalzar, A. \& Ricardo, C, (Eds.). Povos indígenas do Rio Negro: uma introdução à diversidade socioambiental do noroeste da Amazônia brasileira. São Paulo, ISA/FOIRN

Boom, B.M. 1987. The Chácobo Indians and their palms. Principes 30(2): 91-97.

Bailey, K. 1994. Methods of social research. New York, The Free Press.

Berlin, B.; Breedlove, D.E. \& Raven, P.H. 1973. General principles of classification an nomenclature in folk biology. American Anthropologist 75: 214-242.

Berlin, B. 1973. Folk systematics in relation to biological classification and nomenclature. Annual Review of Ecology and Systematics 4: 259-271.

Berlin, B. 1992. Ethnobiological classification: principles of categorization of plant and animals in traditional societies. New Jersey, Princeton University Press.

Cabalzar, A. \& Ricardo, C.A. 2006. Povos indígenas do Rio Negro: uma introdução à diversidade socioambiental do noroeste da Amazônia brasileira. São Paulo, ISA/FOIRN.

Conklin, H.C. 1962. Lexicographical treatment of folk taxomonies. International Journal of American Linguistics 28: 119-141.

Couto, H.H. 2007. Ecolinguística: estudo das relações entre língua e meio ambiente. Brasília, Thesaurus.

Daly, D.C. 1998. Systematics and ethnobotany: what's in a name? Pp. 50-68. In: Fonseca, V.S.; Silva, I.M. \& Sá, C.F.C. (Eds.). Etnobotânica, bases para conservação. Nova Friburgo, EDUR/UFRRJ.

Hartmann, T. 1968. A nomenclatura botânica borôro. Instituto de Estudos Brasileiros/USP, São Paulo.

Lei municipal oficializa línguas indígenas. Instituto de Investigação e Desenvolvimento em Política Lingüística. Disponível em: <http:// www.ipol.org.br/imprimir.php?cod=83> (Acesso em 06/05/2009).

Lorenzi, H.; Souza, H.M.; Costa, J.T.M.; Cerqueira, L.S.C. \& Ferreira, E. 2004. Palmeiras Brasileiras e Exóticas Cultivadas. São Paulo, Nova Odessa.

Miranda, I.P.A.; Rabelo, A., Bueno, C.R., Barbosa, E.M. \& Ribeiro, N.S 2001. Frutos de palmeiras da Amazônia. Manaus, MCT INPA.

Philips, O.; Gentry, A.H. 1993. The useful woody plants of Tambopata, Peru: I Statistical hypotheses tests with a new quantitative technique. Economic Botany 47: 15-32.

Posey, D.A. 1987. Introdução - Etnobiologia: Teoria e Prática. Pp.15-25. In: Ribeiro, D, (Ed.). Suma etnológica brasileira. Petrópolis, Vozes.

Ramirez, H. 2001a. Línguas Arawak da Amazônia Sententrional: Comparação e Descrição. Manaus, EDUA, Universidade do Amazonas.

Ramirez, H. 2001b. Dicionário da Língua Baniwa. Manaus, EDUA, Universidade do Amazonas.

Ribeiro, J.E.L.S.; Hopkins, M.J.G.; Vicentini, A.; Sothers, C.; Costa, M.A.; Martins, L.H.P.; Lohmann, L.G.; Assunção, P.A.C.L.; Pereira, E.; Silva, C.F.; Mesquita, M.R. \& Procópio, L.C. 1999. Flora da Reserva Ducke. Guia de identificação das plantas de uma floresta de terra-firme na Amazônia Central. Manaus, INPA. 